\title{
Nutritional hazards of elimination diets in children with atopic eczema
}

\author{
T J DAVID, E WADDINGTON, AND R H J STANTON \\ Department of Child Health, University of Manchester and Department of Nutrition and Dietetics, Booth Hall \\ Children's Hospital, Manchester
}

SUMMARY. The intake of nutrients over a five day period was studied in 23 children whose atopic eczema was being treated by the avoidance of multiple foods. The results were compared with those from 23 healthy control children not on a diet. Significantly low intakes of calcium were discovered in 13 patients but not in controls. Avoidance of multiple foods is potentially hazardous and requires continued paediatric and dietetic supervision.

It is recognised that atopic eczema improves in some children when certain foods are excluded from the $\operatorname{diet}^{12}$ but curiously the safety of such diets in eczema has never been examined. Potential hazards are often stressed, however, ${ }^{34}$ and inappropriate elimination diets in children with chronic diarrhoea have resulted in failure to thrive caused by restricted caloric intake. ${ }^{5}$ Having established a service for the treatment of atopic eczema by selective exclusion of foods from the diet, we decided to examine the safety of these diets.

\section{Patients and methods}

Selected children with severe, chronic atopic eczema unresponsive to conventional topical treatment by a dermatologist were treated by dietary allergen avoidance. Patients in whom such a diet had failed and had been abandoned were excluded from the present study. This series comprised the first 25 patients successfully maintained on an exclusion diet. In 18 patients suspect foods were identified by the history and the use of tests for specific IgE antibodies. In 7 patients all foodstuffs except one were withdrawn, followed by the reintroduction of single foods one by one. For each patient the dietitian told the parents how to exclude suspect foods and advised on the use of milk substitutes. The diet comprised in part a soya based milk formula (Wysoy or Prosobee) in five patients, and a casein-hydrolysate formula (Pregestimil) in 7 patients. After 6 weeks on the established diet, parents were seen by the dietitian and asked to keep a record for five days of the quantity of all food and drink taken by the child. No instructions were given as to whether this five day period should or should not include the weekend. Parents were not asked to record food intake as it occurred rather than waiting until the end of the day and the dietitians did not visit the homes to make spot checks on whether the recording of information was up to date.

The estimation of quantities was based on household measures. These records and tables of food composition $^{6}$ were used to calculate the daily intake of individual nutrients, averaged over the period. The calcium content of tap water, which is low in Manchester, was not included. The intakes of calories, protein, calcium, iron, folic acid, vitamin A, thiamine, riboflavine, nicotinic acid, and vitamins $C$ and $D$ were compared with the recommended daily amount based on the child's body weight and age. ${ }^{7}$

Twenty five control children matched for age and sex were also studied. They comprised 12 healthy children who had previously been discharged from follow up (febrile convulsion (four), respiratory infection (four), thrombocytopenic purpura (two), urinary infection (one), Kawasaki's disease (one); two children with epilepsy; and 11 healthy siblings of patients currently under the care of the hospital (respiratory infection (four), severe mental handicap (two), recurrent otitis media (two), hip dislocation (two), febrile convulsion (one)). These control children were selected because they were healthy and not on a diet, and had cooperative parents who were thought to be motivated enough to perform a diet survey.

\section{Results}

The families of two patients and two controls failed to return diet records, leaving 23 patients and 23 
Table Subjects with dietary intake lower than the recommended allowance $(R D A)^{7}$

\begin{tabular}{|c|c|c|c|c|c|c|}
\hline & \multicolumn{3}{|l|}{ Patients ( $n=23)$} & \multicolumn{3}{|l|}{ Controls $(n=23)$} \\
\hline & $\begin{array}{l}\text { Less than } \\
100 \% \text { of } R D A\end{array}$ & $\begin{array}{l}\text { Less then } \\
75 \% \text { of } R D A\end{array}$ & $\begin{array}{l}\text { Less than } \\
50 \% \text { of } R D A\end{array}$ & $\begin{array}{l}\text { Less then } \\
100 \% \text { of } R D A\end{array}$ & $\begin{array}{l}\text { Less then } \\
75 \% \text { of } R D A\end{array}$ & $\begin{array}{l}\text { Less than } \\
50 \% \text { of } R D A\end{array}$ \\
\hline Energy & 15 & 2 & 0 & 11 & 1 & 0 \\
\hline Protein & 4 & 0 & 0 & 3 & 0 & 0 \\
\hline Calcium & 14 & 10 & 3 & 4 & 0 & 0 \\
\hline Iron & 6 & 4 & 1 & 16 & 4 & 0 \\
\hline Vitamin A & 1 & 1 & $i$ & 2 & 1 & 0 \\
\hline Thiamine & 0 & 0 & 0 & 1 & 0 & 0 \\
\hline Riboflavine & 1 & 0 & 0 & 1 & 0 & 0 \\
\hline Nicotinic Acid & 0 & 0 & 0 & 0 & 0 & 0 \\
\hline Vitamin C & 1 & 0 & 0 & 1 & 0 & 0 \\
\hline Vitamin D & $14 / 19^{*}$ & 10 & 9 & $18^{*}$ & 17 & 17 \\
\hline Folic Acid & 10 & 5 & 3 & 13 & 6 & 2 \\
\hline
\end{tabular}

* The RDA for vitamin D applies to those aged under 5 years, and four subjects in each group over 5 years of age have been excluded for this nutrient.

controls for study. The patients were aged 6 months to 13 years, median 2 years and the controls were aged 6 months to $12 \frac{1}{2}$ years, median 2 years. Several items of food were excluded in all patients. The median number of foods excluded was 7 . The foods most commonly avoided were, in order of frequency, colouring and preservatives, nuts, milk and all milk products, egg, fish, peas, wheat, soya, and oats. Two patients were receiving vitamin supplements that had been medically prescribed; 8 controls were being given vitamin supplements which had not been prescribed and which were unnecessary for they already had adequate vitamin intakes. The results are shown in the Table. Although the Table includes numbers of subjects with marginally 'low' intakes, clinical significance has only been attached to those with intakes less than $75 \%$ of the recommended daily amount. The social class distributions for the patients were I and II, 10; III, 7; IV and V, 6 and for the controls I and II, 8; III, 11; IV and V, 4.

\section{Discussion}

Using recommended daily amounts as a standard is open to criticism since these do not represent individual nutrient requirements. ${ }^{78}$ The 1979 Department of Health and Social Security report specifically stated that recommended daily amounts should not be used for making judgements about an individual subject's nutritional status and mentions that, 'although the figures were intended to apply to groups of people they have been used mistakenly as recommendations for individuals' ${ }^{7}$ Thus a control group for comparison is essential, though similar studies in the past have not included a control group and have. relied solely on the figures. ${ }^{9} 10$ Our controls represented a particularly well motivated group. The same applied to the patients, for only families who were well motivated and thought capable of managing a diet were offered dietary treatment. The social class distribution of the two groups was similar. The fact that 8 controls were given vitamin supplements without medical advice may suggest a hidden difference between the patients and controls, however vitamin supplements were excluded from the diet of 16 patients on the grounds that they contained colouring agents or preservatives. We do not know how many patients were receiving vitamin supplements before the diet.

We do not know at what intake level below the recommended daily amount a subject should be considered 'at risk' of undernutrition-our choice of below $75 \%$ is arbitrary. The diet survey method itself suffers from serious drawbacks. The standard method using household measures to estimate quantity of intake is crude. The alternative, to issue parents with scales to weigh all food accurately, would not only be impractical but would probably alter what the child eats. (The latter argument may also apply to any prospective diet survey.) Furthermore, although it is not clear whether a longer period would have been advantageous, ${ }^{11}$ five days is a short study period.

With these caveats in mind, the chief finding of this survey was that 13 of 23 patients but no controls had an intake of calcium less than $75 \%$ of the recommended daily amount. Indeed, shortly after the completion of the study a further patient stopped drinking her casein hydrolysate milk formula without telling us, and developed rickets. It is not widely known that even where avoidance of cows' milk and milk products is offset by the use of milk substitutes, these substitutes, whether based on soya or casein hydrolysate, contain only half as much calcium as cows' milk. The supposedly 'low' intakes of vitamin $D$ have been disregarded on the grounds that the chief source of vitamin D is not dietary but is due to the action of ultraviolet light on the skin. Furthermore, patients receiving a milk 
substitute are less likely to become vitamin D deficient because of the 30 fold excess of vitamin D in these milk substitutes when compared with cows' milk. Similar numbers of patients (five) and controls (four) had significantly low iron intakes. It seemed that any potential for iron deficiency in the patients was offset partly by the fact that they often ate larger meat portions to compensate for other foods, and also because the milk substitutes used contained 10 to 20 times more iron than cows' milk. Similar proportions of patients and controls had low intakes of vitamin A or folic acid.

Clearly elimination diets are potentially hazardous. The implication of this study is that in addition to an initial visit to the dietitian to receive advice on food exclusion, further visits are required to ensure the child remains on a nutritionally adequate diet. We are increasingly seeing children who have been on elimination diets after visits to self referral laboratories ${ }^{12}$ which rely on identification of food allergy by hair analysis or other suspect methods. Five of the 25 patients in this study had previously been on these regimens. Such diets when unsupervised by a paediatrician or dietitian are even more potentially hazardous, although in all five cases the diet had been abandoned because it was unsuccessful.

We thank Dr D Burman. Dr R Newton, Professor J Dobbing and Professor R D H Boyd for their help, and Mrs C Sanders for typing the manuscript.

\section{References}

${ }^{1}$ Juto P, Engberg S, Winberg J. Treatment of infantile atopic dermatitis with a strict elimination diet. Clin Allergy 1978;8:493-500.

2 Hill DJ, Lynch BC. Elemental diet in the management of severe eczema in childhood. Clin Allergy 1982;12:313-5.

${ }^{3}$ Goldsborough J, Francis DEM. Dietary management. In: Proceedings of the second Fisons food allergy workshop. Oxford: Medicine Publishing Foundation, 1983:89-94.

${ }^{4}$ Workshop Summary. In: Proceeding of the first food allergy workshop. Oxford: Medical Education Services Ltd., 1980: 106-8.

${ }^{5}$ Lloyd-Still JD. Chronic diarrhea of childhood and the misuse of elimination diets. J Pediatr 1979;95:10-3.

6 Paul AA, Southgate DAT. The composition of foods. 4th ed. London: Her Majesty's Stationery Office, 1978.

7 Recommended daily amounts of food energy and nutrients for groups of people in the United Kingdom. Report on Health and Social Subjects, No. 15. London: Her Majesty's Stationery Office, 1981.

${ }^{8}$ Short SH, Short WR. Four-year study of university athletes' dietary intake. J Am Diet Assoc 1983;82:632-45.

${ }^{9}$ Carter P, Carr D, van Eys J. Coody D. Nutritional parameters in children with cancer. J Am Diet Assoc 1983:82:616-22.

${ }^{10}$ Harris RJ, Armstrong D, Ali R, Loynes A. Nutritional survey of Bangladeshi children aged under 5 years in the London borough of Tower Hamlets. Arch Dis Child 1983;58:428-32.

1 Stuff JE, Garza C, Smith EO'B, Nichols BL, Montandon CM. A comparison of dietary methods in nutritional studies. Am J Clin Nutr 1983;37:300-6.

12 Anonymous. Self referral laboratories (editorial). Lancet 1983;i:802.

Correspondence to Dr T J David, Booth Hall Children's Hospital, Charlestown Road, Blackley, Manchester M9 2AA.

Received 11 January 1984 